\title{
Propuesta de estudio SEMiótico PARA LOS MURALES De Bonampak, Chiapas, MÉXico
}

\author{
Proposal for a Semiotic Approach to the Bonampak Murals, Chiapas, Mexico \\ Sophia Pincemin-Deliberos \\ Mauricio Rosas-y-Kifuri
}

Resumen: Eneste trabajo se describey analiza la escena representada en los muros este, sur yoeste del cuarto l de los murales de Bonampak, llamada "la presentación del heredero," utilizando las calcas hechas en 1988 y revisadas en los dos últimos años, así como elementos teóricos y metodologías de la semiótica visual.

Palabras clave: murales mayas, semiótica visual.

Abstract: This paper describes and analyzes the scene represented in the east, south and west walls in Room 1 of Structure 1 or "Paintings Building" at Bonampak, Chiapas, México. We'll use our 1988 drawings revisited in the last two years, and theoretical elements and methodologies from visual semiotics.

Keywords: Mayan paintings, visual semiotics.

\footnotetext{
Sophia Pincemin Deliberos, profesora de la licenciatura en antropología social de la Facultad de Ciencias Sociales de la Universidad Autónoma de Chiapas, México. Líder del cuerpo académico Estudios Mesoamericanos. Doctora en investigación antropológica por la UNAM. Temas de especialización: arqueología e iconografía maya. Correo electrónico: sophiamayas@gmail.com.

Mauricio Rosas y Kifuri, estudiante del doctorado en estudios regionales de la Universidad Autónoma de Chiapas, México. Docente en la licenciatura en antropología social de la Universidad Autónoma de Chiapas. Temas de especialización: antropología de México, antropología de la alimentación e iconografía. Correo electrónico: mrosaskifuri@gmail.com.
}

Enviado a dictamen: 16 de mayo de 2013. Aprobación: 06 de agosto de 2013.

Revisiones: 2. 
E n la actualidad vivimos en un mundo en el que el sentido de la vista se privilegia sobre los demás. Todo un universo de imágenes nos rodea sin que seamos siempre conscientes de él, aunque reaccionamos de una manera u otra según nuestras culturas. Cuando vemos a otro ser humano, el conjunto de conceptos que visualizamos nos informa sobre su sexo, edad, estado de ánimo, condición social o sobre la actividad que realiza. Este conjunto organizado de signos y símbolos visuales puede ir acompañado de otros sistemas de comunicación: sonoros -música, ruidos, lenguaje hablado o cantado-, olfativos perfumes o humos con diferentes olores - e inclusive gustativos - alimentos que deleitan el paladar o le son repulsivos-. La decodificación que efectuamos es instantánea e instintiva dentro de los sistemas de comunicación que nuestra sociedad ha elaborado y nos permite una identificación suficiente para la toma de contacto y el uso apropiado de las actitudes y el lenguaje correspondientes. En cambio, para las épocas pasadas sólo nos queda el conjunto de signos y símbolos visuales de los cuales ignoramos el código en el que están cifrados. En todo el área mesoamericana - casi toda la República mexicana, Guatemala, Belice, Honduras, El Salvador y parte de Nicaraguase han descubierto figurillas de barro, esculturas monumentales de piedra, pinturas murales y códices que representan figuras humanas y divinas de la época prehispánica. Estas imágenes forman parte de nuestro patrimonio cultural tanto tangible - sus soportes, como figurillas, pinturas, cerámicas o estelas - , como intangible - las ideas que representan- Trabajando con objetos hechos por hombres del pasado, nos encontramos estudiando artefactos que caben en dos categorías, la de objeto arqueológico en sí y la de manifestación artística. Ambas se pueden estudiar desde un punto de vista puramente arqueométrico a la manera occidental, es decir, comprobando su fechamiento, la técnica de elaboración o los materiales que lo componen. Este tipo de estudio está muy arraigado entre los arqueólogos. Sin embargo, cada vez se va más allá del objeto en sí para encontrar cuál podría ser su significado para sus autores y buscar la información implícita en él contenido —-por ejemplo, étnica, social, estética o económica-.

Por otro lado, debemos reconocer que no conocemos prácticamente ningún arte antiguo en su forma completa: ni el arte de la Grecia clásica, privado de una policromía sorprendente que constituía una de sus características más sobresalientes y, por ende, tan mutilado; ni el arte medieval o el maya, despojados también de sus revestimientos polícromos, por lo que debemos hacer un esfuerzo para tratar de entender estas artes. Tenemos que reconstruir a la vez el sentido que los autores dieron a sus obras y el valor que tenían para sus contemporáneos al momento de ser ejecutadas, es decir, tenemos que determinar sus valores intrínsecos y reconocer la validez de otros sistemas para concebir el mundo a través de la experiencia técnica y social de una época y a través de su particular modo de asociar diferentes signos. Esto, para Pierre Francastel, es "lo que constituye la naturaleza misma de la obra de arte. Porque los signos no son el doble o el reflejo de lo real. La figuración plástica no es jamás la transposición a la pantalla plástica de una realidad exterior al espíritu" (Francastel, 1988: 186).

Más adelante, en su texto, el mismo autor se maravilla de que se puedan mostrar formas diferentes de pensar y actuar con los mismos instrumentos básicos a disposición del ser humano:

Lo que cuenta, finalmente, no es la analogía exterior de los signos, la más fácil de descubrir, sino el hecho de que con instrumentos idénticos ciertos hombres logran expresar una visión diferente pero también explicativa del mundo (Francastel, 1988: 186).

Asimismo, bajo la forma que asumen, labradas en piedra, madera, hueso o cualquier otro material duro, pintadas en rocas, paredes, cerámica o bordadas en textiles, las imágenes forman un texto compuesto por varios elementos que transmite una comunicación visual. Así pues, las imágenes están dispuestas bajo un orden que es susceptible de ser estudiado y analizado para descifrar las claves de su representación. Dicho estudio se conoce generalmente bajo el término "iconografía" - del griego 
eikón, imagen, y graphein, escribir- Hasta hoy, se han estudiado estas imágenes sobre todo desde el punto de vista aislado del historiador del arte, del arqueólogo, del epigrafista o del coleccionista, pero no se ha tomado en cuenta que son importantes no solamente en sí mismas, sino porque en ellas está cifrado el código de comunicación visual que los antiguos mesoamericanos en general, y los mayas en particular, utilizaban como urdimbre de todas sus actividades.

Por otra parte, en los murales, a diferencia de las estelas o las vasijas en las cuales el número de participantes es más limitado, se pueden apreciar diversas escenas relacionadas con rituales políticos, religiosos y bélicos en las cuales interactúan decenas de personas de la élite gobernante, sus familiares y sus aliados. Así, aun si sabemos que las representaciones nos muestran una cierta categoría de personas en momentos especiales y que nuestra percepción es diferente a la de los mayas, el estudio minucioso de las imágenes en sí mismas nos puede ayudar a entender partes del pasado.

En este artículo, como ejemploy primer acercamiento a una visión interdisciplinaria de las imágenes mayas prehispánicas, se describe y analiza la escena representada en los muros este, sur y oeste del cuartol de los murales de Bonampak, llamada "la presentación del heredero", utilizando elementos teóricos y metodologías de la semiótica visual, tomando en cuenta que nuestra comprensión del arte maya siempre será parcial y sujeta a múltiples modificaciones

\section{Bonampak y sus murales}

Bonampak es un sitio pequeño en la Selva Lacandona, en México, cerca de la frontera de este país con Guatemala (ver mapa 1), pero es mundialmente conocido porque en 1946 fueron dadas a conocer las pinturas murales mayas mejor conservadas y más extensas conocidas.

Tiene un patrón de asentamiento disperso y dependía en algún momento de Yaxchilán, ubicado a unos 30 kilómetros de allí, en el margen del río Usumacinta. Arqueológicamente, varias expediciones han trabajado el sitio desde la publicación de Ruppert, Thompson y Proskouriakoff en los años cincuenta, hasta las últimas excavaciones del Intituto Nacional de Antropología e Historia (INAH) encabezadas por AlejandroTovalín, quien escribe que la historia constructiva de Bonampak "debió abarcar desde finales del siglo V hasta finales del siglo VIII o principios del IX" (2013: 104), pero señala que:

La mayor parte de la información histórica del sitio pertenece al periodo final de ocupación, es decir, al último cuarto del siglo VII y que corresponde al gobierno de Yajaw Chan Muwan II, quien manda construir el edificio de las Pinturas con sus murales y sus tres dinteles labrados [...] y erigir las únicas cuatro estelas con escenas labradas que permanecen in situ (Tovalín, 2013: 98).

Sabemos por las inscripciones que Yajaw Chan Muwan II gobernó a partir del año 776 d. C. hasta por lo menos el año 792 d. C.

La parte más conocida del sitio de Bonampak se encuentra alrededor de una plaza y de una acrópolis sobre la cual se erigieron varios edificios (ver mapa 2). En el conjunto general de la acrópolis, la Estructura les secundaria, ya que el edificio principal era la Estructura 2, al centro de la escalinata, como hemos mostrado en un trabajo anterior (Pincemin y Rosas, 2005).

Por lo que toca a los murales de Bonampak, tenemos que decir que, hasta la fecha, la Estructura l es el único edificio maya que ha conservado casi íntegramente sus pinturas interiores, las cuales conforman un conjunto iconográfico cerrado, temporal y socialmente, a lo largo de los 250 metros cuadrados de pinturas que cubren los muros y las bóvedas de los tres cuartos. Este único grado de preservación se debió a filtraciones de agua que dejaron sobre los muros una capa de carbonato de calcio que impidió el desprendimiento de la capa pictórica. Más tarde, con la protección que se dio al edificio, la capa de carbonato de calcio se secó volviéndose opaca, por lo que ya no se podían apreciar los murales. A partir de los trabajos de limpieza llevados a cabo por la Dirección General de Conservación y Restauración del Patrimonio Cultural del INAH de México, de 1984 a 1988, Sophia Pincemín hizo calcas de 
todos los elementos pintados que sirvieron de base a estudios iconográficos y epigráficos de los murales, a cargo de ambos autores, de tal manera que apareció un gran número de datos nuevos y se definieron con más precisión los trazos anteriormente mencionados, lo que condujo a interpretaciones a veces diferentes de las aceptadas hasta ese momento.

Mary Ellen Miller, cuya tesis de doctorado The Murals of Bonampak, publicada en 1986, anunciaba que su trabajo era el último testimonio sobre las pinturas, trabajó con National Geographic y medios electrónicos para presentar en 1995 una versión reconstruida de algunas escenas presentación del heredero del cuarto 1, presentación de los prisioneros del cuarto $2 \mathrm{y}$ autosacrificio del cuarto 3-. Por otra parte, y dado que las antiguas copias a color de Villagra y de Tejada hechas en los primeros años del descubrimiento, así como la de Rina Lazo en el Museo Nacional de Antropología de México, tenían lagunas, la investigadora norteamericana emprendió en 1995 el proyecto Bonampak Documentation Project, "to record every detail of the murals before they disappeared" (Yale Peabody Museum, s.f.). A partir de su integración al proyecto en 1999, Heather Hurst hizo una copia de los murales a mitad de tamaño.

En ese mismo tiempo, el Instituto de Investigaciones Estéticas (IIE) de la UNAM estaba realizando el proyecto La Pintura Mural Prehispánica en México, cuya primera publicación fue sobre Teotihuacán (1996), a la cual siguió un trabajo interdisciplinario sobre el área maya cuyos primeros dos volúmenes contemplaban de manera exhaustivalos murales de Bonampak. Estos dos proyectos se basaron en la limpieza de 1984-1988 y las subsiguientes para también avanzar nuevas interpretaciones. Houston y Miller, por ejemplo, en el volumen del IIE, proponen nuevas lecturas del texto jeroglífico de la Serie Inicial del cuarto 1 y de la cláusula de la batalla en el cuarto 2 y, en este caso, reconocen que nuestra propuesta de fecha, 19 de julio del 786 d. C. (Rosas, 1988: 42; Pincemin y Rosas, 1994: 132, 1998: 56, 2005: 12), es más lógica que la propuesta por Arellano (1998: 277) cuando escribe:

Mauricio Rosas (1988: 42) propuso una lectura de 13 men 13 chen, que puede localizarse en 9.17.15.12.15.
Establecida menos de cinco años antes de la Serie Inicial y tal vez relacionada con las imágenes de la Estela 3, esa lectura sería razonable (Pincemin y Rosas, 1998: 253).

\section{Semiótica y semiótica visual}

Una de las propuestas básicas para entender las manifestaciones artísticas es la de E. Panofsky (1984) en su diferenciación entre el estudio de la iconografía - análisis de las imágenes - y de la iconología -interpretación del significado intrínseco-. A. Leroi-Gourhan (1965) propone algo similar para el llamado "arte prehistórico". Allí se renuncia de inicio a la comprensión de la leyenda concreta que pudieron transmitir las manifestaciones artísticas, pero se considera que el simbolismo es un elemento dependiente de la estructura de la sociedad y de su relación con el entorno, por lo que resulta posible realizar preguntas relacionadas con la utilidad social del arte, puesto que las representaciones están, en último término, condicionadas por el propio funcionamiento de la sociedad. Este simbolismo, en el caso que nos ocupa, se encuentra en los signos distintivos que marcan la situación social de una persona en las grandes etapas de la vida —iniciación, bodas, muerte - o su situación tecno-económica - la infinita variedad de los vestidos y adornos de los guerreros de diferentes grados: gobernantes, nobles, mercaderes, artesanos o deidades-; es decir, en todas las representaciones del mosaico de funciones sobre el cual reposa la vida material de un grupo humano. Estas dos propuestas se incorporan también en los nuevos tipos de análisis que se hacen a partir de la semiótica, disciplina que se ocupa del estudio de los procesos mediante los cuales algo se utiliza como representación de otra cosa, sustituyendo a esa cosa en algún sentido. El concepto de representación debe entenderse también en sentido amplio, no meramente como copia o plasmación gráfica, sino como modelos o sistemas de signos que median con el objeto de conocimiento, generando así configuraciones dinámicas en nuestra experiencia de interacción con el mundo. La naturaleza misma de la percepción nos exige 
enfocar, es decir, dejar de lado muchas cosas, consciente o inconscientemente, por lo que, para Umberto Eco, "los signos icónicos reproducen algunas condiciones de la percepción del objeto una vez seleccionadas por medio de códigos de reconocimiento y anotadas por medio de convenciones gráficas" (1986: 174).

Dado que el término semiótica significa de manera general "teoría de los signos", es importante ver cuáles han sido los enfoques teóricos sobre los signos como categoría general de significado.

Para algunos el signo es, en principio, un objeto construido; para otros [...] es un objeto observable y otros sólo toman en cuenta sistemas de signos previamente establecidos; entre ellos, algunos se limitan a los sistemas intencionalmente construidos (señalización en carreteras, etc.), mientras que otros extienden esas nociones a la investigación de los sistemas de significación implícitos en toda práctica social (los mitos, los ritos, las prácticas rituales) (Marty, s. d.).

Para estas diferentes teorías, el signo tiene como función comunicar ideas, lo que implica que se debe tener un objeto - de lo que se habla-, un emisor, un receptor, un medio de transmisión y un código. Para su estudio se han generado varias teorías entre las cuales sobresalen actualmente dos grandes tendencias. La primera es binaria, es decir, está fundada sobre pares opuestos tales como significante/significado; en ella encontramos a A.J. Greimas, F. de Saussure y L. Hjelmslev. Para Saussure existe una imagen acústica, que llama el "significante", y un concepto, el "significado", dos elementos íntimamente ligados que se requieren mutuamente. La segunda teoría es tríadica y está representada fundamentalmente por Peirce. Para este autor, todo signo está constituido por tres instancias: el signo - lo que representa-, el objeto - lo que se representa- y el intérprete que produce la relación entre ambos. Charles Peirce pensaba también que existía una relación de semejanza entre los iconos y los objetos a los cuales se refieren (Eco, 1986: 169). En la actualidad, existen también varias teorías que intentan efectuar una síntesis entre estas dos, como las de Umberto Eco o las de Yuri Lotman y la escuela de Tartu.

[La significación] es la relación entre el significante y el significado del signo [...] En la semiótica de Peirce, el significado no reside en el signo, sino en la relación entre los signos [...] Se trata de los signos tal y como se encuentran en el proceso interpretativo. El interpretante a su vez, al ser signo, remite a otro interpretante y así al infinito. Cada vez que el signo es interpretado se convierte en otro signo que actúa como interpretante (Brozzoli y Sánchez, 2003: 172).

Lotman, en particular, ha insistido en ver el acto comunicativo no como una transmisión pasiva de información, sino como una recodificación o, más precisamente, como una traducción. Desde el informacionalismo ya se había sostenido que el receptor debe reconstruir el mensaje recibido, por lo que la incomprensión o la comprensión incompleta no son productos laterales del intercambio debidos al ruido -irrupción del desorden, de la entropía, de la desorganización en la esfera de la estructura de la información - en el canal de la comunicación y, por tanto, algo no inherente a la comunicación, sino que, por el contrario, corresponden a su esencia real. Dicha decodificación no puede encontrarse aislada de los otros elementos de la cultura, sino que se debe dar en un sistema o un conjunto de sistemas - que el mismo Lotman bautizó "semiosfera" - que permitan poner de manifiesto los lenguajes que subyacen tanto a nivel superficial - descriptivo-, como profundo explicativo-, a los textos que conforman esta cultura. Por su parte, en La estructura ausente (1986) Umberto Eco plantea la hipótesis de que todos los sistemas culturales son sistemas de signos, es decir, que la cultura es esencialmente comunicación; en este sentido, entonces, podemos entender como "textos culturales" a cualquier proceso de comunicación - hablado, escrito, visual, olfativo, etcétera- que tiene lugar en una sociedad independientemente de la base que lo soporte.

Por otra lado, Lévi-Strauss (citado en Ochoa, 1986: 9) señala que no existen fenómenos naturales sino 
fenómenos conceptualizados y filtrados por normas lógicas y afectivas que participan de la cultura. Existe entonces un aparato simbólico, específico del ser humano, para servir de puente entre el hombre y el mundo, para poder representar los elementos de la realidad por otros elementos, los signos, que no hay que confundir con lo que llamamos "la realidad", que es diferente para cada una de las culturas y para la gente dentro de dichas culturas. Cada época marca, entre otros puntos, visibilidades, saberes, percepciones y estética. Así, ciertas partes de nuestro entorno son reconocidas como entidades visualmente organizadas, y reconocer esta organización visual implica una operación semiótica mediante la cual adscribimos a algo algún tipo de sentido, orden o relación entre sus partes. El mundo debe entonces entenderse dentro de sistemas dinámicos e interactivos de partes, donde las partes y los componentes están conectados de forma organizada, a la vez que se ven afectados por estar en dicho sistema, de tal modo que el todo es más que la suma de las partes.

Sin embargo, siempre hay que tener en cuenta que estos sistemas han sido creados por personas con pensamientos, valores y sentimientos diversos y, por lo tanto, no necesariamente corresponden a nuestra manera de percibirlos.

Debemos entonces estudiar los signos primeramente en su dimensión significante - la parte más visible, en estos casos los dibujos o esculturas - para tratar de acercarnos a sus significados, estudio que se relaciona entonces con la semiótica visual.

Benveniste mencionó que había dos características fundamentales en un sistema semiótico. La primera se trataba de:

un repertorio finito de elementos caracterizados por ser (1) discretos, es decir, cada elemento es delimitable y diferenciable de los otros; (2) finitos, sin ser por tanto abundantes en número; (3) combinables, lo que les permite entrar en relación, y (4) jerarquizables, por lo que es posible distinguir entre unidades mayores/ menores, simples/complejas, no todas las cuales son portadoras de significación (Benveniste, 1977).
La segunda característica de estos sistemas es "el estar regido por unas reglas de dispersión que definen ciertas normativas de transformación y asociación de los elementos del sistema semiótico, que definen diferentes niveles y entidades significativas y representativas" (Benveniste, 1977).

La semiótica visual nos permite también adentrarnos en la semiótica de la cultura, para la cual el comportamiento humano es una forma de comunicación: en situaciones codificadas permite situar y determinar la actuación de un individuo en relación con otros. Para Herón Pérez (2011) existen tres componentes de dicho comportamiento: el verbal - las palabras que se dicen-; el gestual - los gestos que se hacen - llamado también kinética; y los accesorios indumentaria, como vestidos y adornos, y ajuar, desde el espacio hasta los objetos que lo configuran-. Estos componentes varían según una serie de factores, como el tipo de participantes -masculino/femenino, joven/ anciano, etcétera-, la cantidad de participantes, las relaciones entre ellos o el tipo de evento. Las señales que conforman estos componentes pueden ser generales o muy específicas, y algunas muestran la intención de comunicarse, mientras otras son expresivas o simbólicas.

La kinética es enfocada hacia el cuerpo: su objetivo es estudiar los movimientos corporales $y$, en particular, la gestualidad. En efecto, dentro de la amplia gama de movimientos corporales, los gestos o kinemas son los más numerosos. Son señales mandadas, a través de un acto voluntario o no, a alguien. La interpretación de los kinemas depende de la cultura en la que se enclava y del contexto en el cual se producen. Un elemento esencial de estos contextos es la llamada proxémica, que es la dimensión espacial como lo escribe Pierre Guiraud:

Expresiones como mantenerse a distancia, guardar las distancias, ocupar una posición importante [...] demuestran la importancia de la posición y de la distancia entre los miembros del grupo dentro de la organización social y en la comunicación entre individuos (Guiraud, 1986: 86). 
La proxémica muestra el espacio social y, para Guiraud (1986: 88 y ss.), hay que distinguir entre la distancia entre los interlocutores y su posición recíproca. En el primer caso existen, según el autor, ocho distancias que se pueden agrupar en cuatro tipos: la distancia íntima, la personal, la social y la pública. En cuanto a las posiciones, se valora la cercanía o lejanía en una interacción cara a cara entre dos o más personas, así como la postura — parado o sentado-, las oposiciones arriba/abajo o izquierda/derecha, y otras facetas espaciales. El autor citado escribe al respecto que "los rangos, los lugares y las distancias están cargados de sentido en los encuentros diplomáticos o en las ceremonias públicas" (Guiraud, 1986: 95).

Consideramos así que el análisis debe ir desde lo que se ve - descripción- a lo que subyace explicación-, o como lo propone Chomsky, de la estructura superficial a la estructura profunda. En el caso de los mayas prehispánicos, podemos hacer lo primero de manera más sistematizada y, por ello, hay que estudiar la cantidad más grande de atributos posibles, es decir, no solamente el objeto o el dibujo en sí mismos, sino también el contexto cultural y natural en el cual aparecen, por lo que es necesario establecer no solamente una tipología específica de cada uno de los rasgos, sino asociarla al objeto en su conjunto, a su contexto, así como a las fuentes arqueológicas, etnohistóricas o etnológicas. ${ }^{1}$

\section{Un ejemplo de los murales de Bonampak}

Lo que más se conoce del sitio es la parte remodelada por el último gobernante, Yajaw Chaan Muwan II, a finales del siglo VIII. Sobre una acrópolis natural, en la primera plataforma se construyeron tres edificios: del principal, en el centro, sólo quedan algunos restos de muros, mientras que los dos situados a los lados continúan en pie. La llamada Estructura 1o Templo de las Pinturas es el único edificio del área maya, hasta hoy, que conserva casi intactas todas sus pinturas interiores, del piso al cierre de bóveda, con una superficie aproximada de 250 metros cuadrados. La fachada también estaba pintada $\mathrm{y}$, con base en los restos de pigmentos todavía in situ, podemos decir que la decoración consistía en paneles verticales de rojo y blanco (ver figura 1), rematada en la parte superior por una banda blanca con glifos en negro de los cuales sólo quedan tres fragmentos. La parte del techo estaba cubierta por una escena de estuco de la cual quedan restos de una figura humana y un pez, con tres nichos que albergaban esculturas del mismo material que probablemente representaban al gobernante.

El edificio tiene tres cuartos separados, cada uno con una entrada coronada por un dintel grabado y con restos de pintura. Las escenas empiezan encima de una banqueta de unos 0.8 metros de alto y los peraltes de dicha banqueta están también pintados con motivos geométricos a excepción del cuarto 2. La distribución espacial general de la pintura que se lee, como la escritura, de arriba hacia abajo y de derecha a izquierda, muestra representaciones relacionadas con el cielo en los cierres de la bóveda, imágenes de deidades y ancestros en la parte superior de la bóveda, así como diferentes escenas con personajes humanos en lo que queda -intradós y muros-.

Siguiendo el orden de las cámaras de este a oeste, encontramos que en el cuarto 1 hay tres escenas con personajes humanos - arriba, "la presentación del heredero" y "la vestimenta"; abajo "música y bailes"-; en el cuarto 2, dos escenas, "la batalla" y "el juicio de los prisioneros"; y en el 3, una sola escena que recibe el nombre de "rituales y sacrificios". Cabe aclarar que, salvo en el último caso, seguimos la nomenclatura comúnmente utilizada para denominar estas representaciones así como para numerar los personajes - FH por figura humana con el número del cuarto y el secuencial del personaje: $\mathrm{FH} \mathrm{l} / \mathrm{l}$ es así el primer personaje del cuarto 1-, como propusieron Adams y Aldrich en 1978.

Para este artículo, y como ejemplo, hemos decidido trabajar con la primera escena del cuarto 1, llamada "la presentación del heredero". Se trata de un registro horizontal cerrado delimitado por una gruesa línea roja en la parte superior y en los lados este y oeste, así como por una banda roja con una cinta blanca en el medio que ocupa los intradós este, sur y oeste, y que enmarca un texto glífico en la parte inferior. El fondo de color 
naranja no es totalmente liso ya que hay variaciones en el aplanado que dan algunos relieves. Todas las interpretaciones que se han hecho hasta ahora están de acuerdo con que se trata de un evento social durante el cual el gobernante y su familia están presentando a su heredero a los dignatarios bajo su mando.

Tenemos un total de 21 participantes distribuidos en varios grupos, de los cuales 18 son hombres, dos mujeres y un niño de sexo indeterminado, aunque probablemente sea varón. A excepción de este último, todos parecen estar en el mismo rango de edad: jóvenes adultos entre 20 y 40 años, ya que no se nota ningún signo exterior de vejez. Al respecto, sin embargo, cabe hacer notar que, salvo raras excepciones -en particular las representaciones del dios $\mathrm{M}$ y algunas muy específicas de ancianos-, en la iconografía maya los personajes representados pertenecen a esta categoría etaria, lo que es, probablemente, un canon establecido. Conforman dos grandes grupos repartidos en cuatro niveles: el primero de los cuales es el del piso - muro sur-, el segundo el escalón del muro este, el tercero la plataforma del trono y el cuarto, el trono mismo (ver figura 2).

Las cabezas de los personajes del nivel l están a la altura del trono - nivel 4-, mientras que las de los personajes del nivel 2 corresponden más o menos a la altura del torso de los del nivel 4. En este último, la cabeza del personaje central es más alta que la de los que lo rodean, por lo que visualmente tenemos establecida una primera jerarquía que podemos esquematizar en el croquis que se muestra en la figura 3 (ver figura 3).

El primer gran grupo se compone de 14 personajes con grandes capas blancas ribeteadas por una banda de motivos geométricos en negro y cerradas por una o tres conchas de Spondylus sp., lo que nos habla de la utilización de accesorios - las capas - que podríamos designar como "obligatorios", aun si cada una es diferente en su realización - diferencias en los amarres de las conchas, largo de las capas o diseños diferentes en los ribetes, por ejemplo-. A su vez, se divide en tres subgrupos: el primero, en el intradós este, está conformado por cuatro figuras humanas de pie que se encuentran en un escalón más arriba que los otros y que corresponden al nivel 2 de nuestro croquis (ver figura 4).

Tres de ellos están de frente con las cabezas de perfil mirando hacia su izquierda, mientras que el último se muestra de perfil. Son los únicos de esta escena que tienen pintadas cláusulas glíficas (CG): las tres primeras con tres glifos y la última con dos. Cabe hacer notar aquí que CG 1/3 es un cartucho, mientras que las otras están pintadas directamente sobre el fondo naranja. Aunque sus tocados son todos diferentes y, por lo general, se trata de turbantes anudados de distintas formas, todos tienen una pluma verde que sobresale hacia adelante en el caso de los personajes 1, 2 y 4, y hacia atrás en el 3. Todos visten una falda corta de diseño y colores variados con ex - taparrabos-. Los gestos de las manos indican una posición de reposo o de expectativa y no muestran interacción entre ellos. FH 1/4 es el más dinámico y parece querer caminar para bajarse del escalón, por lo que sirve así de enlace con el muro siguiente.

Los demás personajes - FH 1/5 a 1/14- se encuentran en un nivel más abajo y, para compensar el espacio visual, se encuentran marcos verticales para cláusulas glíficas que dan también movimiento a la escena, aunque dichos glifos nunca fueron pintados.

El segundo subgrupo, conformado por otros cuatro personajes, se encuentra en la parte este del muro sur (ver figura 5). Las figuras están de pie en un nivel de piso (1 en nuestro croquis representado en la figura 3) y sus ademanes muestran una conversación entre tres nobles, uno de perfil y los otros de frente pero mirando hacia su izquierda, y un cuarto de frente y volteado hacia su derecha y sus interlocutores; la discusión más animada se da, al parecer, entre $\mathrm{FH} 1 / 6$ y 1/8, ya que el movimiento de las manos muestra un énfasis más grande en el apoyo a los argumentos verbales presentados, mientras sus dos compañeros están atentos a lo que se dice.

Los tres primeros personajes visten falda corta y sus tocados de turbante presentan una larga pluma verde, lo que les relaciona con el subgrupo anterior; en cambio, el último, FH l/8, es el único de toda la escena que presenta una vestimenta larga, y es el primero que tiene un tocado diferente, una diadema de la cual sale un penacho de plumas y una máscara fantástica de 
deidad con nariz protuberante. Además, cierra este cuadro dando la espalda al que sigue, quien tiene parte del cuerpo opacándole.

$\mathrm{La} \mathrm{FH} \mathrm{1/9} \mathrm{es} \mathrm{el} \mathrm{punto} \mathrm{focal} \mathrm{del} \mathrm{siguiente} \mathrm{subgrupo}$ formado por seis personajes (ver figura 6). Este noble —FH 1/9-, por sus ademanes, está discutiendo con FH 1/12; mientras los otros están escuchando los argumentos —brazos cruzados o de lado-, el personaje 12 está levantando la mano. $\mathrm{FH}$ 1/10 está un poco retirado de los demás - tiene más espacio a su alrededor-y es el único personaje de este cuadro que tiene el ojo agredido; los que siguen forman un bloque más compacto en el que la posición de los brazos indica una sutil distribución de la proxémica: ${ }^{2} \mathrm{FH}$ 1/13, por ejemplo, se encuentra un poco más hacia el frente que los dos que lo rodean, ya que su brazo derecho "invade" el espacio de FH 1/12 y su brazo izquierdo, con la capa, oculta el derecho de FH 1/14. Este último personaje es muy interesante porque, por una parte, es el más cercano a la plataforma que soporta el trono y, por otra, está vestido con una falda de piel de jaguar - símbolo de rango entre los mayas-y ostenta orejeras largas del mismo material. Además, en comparación con los demás nobles, y en particular con su vecino, está muy delgado. Estos elementos nos han permitido proponer que estábamos frente a un guerrero de alta jerarquía.

En este muro también empieza la escena del trono con un grupo formado por un noble que porta una figura más pequeña sobre una plataforma alta. Aunque tiene el cuerpo de frente, su cabeza está rotada 90 grados hacia el muro oeste y hacia los personajes sobre el trono (ver figura 7), y parece presentar su carga a los personajes de los cuadros precedentes.

De esta forma, el artista resolvió el problema de enlazar este muro con el siguiente para formar un solo cuadro. El pequeño, por las proporciones del cuerpo del personaje, estimamos que se trata de un infante de unos seis u ocho años, y no de un bebé. Sentado de tres cuartos, tiene el brazo izquierdo detrás del hombro de su portador y está vestido con una túnica larga con mangas transparentes con motivos en tonos verdes. Su pelo rojizo está peinado en una especie de cola de caballo con mechones diferenciados y ha perdido el ojo. Es el único que presenta una edad diferente a la de los demás y tiene la cabeza a la misma altura que el personaje sentado en el trono a la izquierda del principal.

Todas las figuras del muro sur tienen reservado el espacio para sus respectivas cláusulas, pero los glifos nunca fueron pintados. En esta escena existen cuadros de composición formados por grupos de personajes, un centro de convergencia y un arreglo rítmico de éstos. Parece que los personajes están alineados como en formación militar para pasar revista, pero, si se examina con detenimiento, uno se da cuenta de que no es el caso. Por otro lado, un espectador puede preguntarse por qué ninguno de ellos está aparentemente viendo hacia los personajes principales ni está atento a lo que sucede. En el segundo caso, proponemos que estamos en el "antes de", es decir, no se está representando el evento en sí, sino momentos previos. Podemos suponer que está a punto de suceder, quizás están en la "tercera llamada". En cuanto a la primera reflexión, se observa que los lados norte de la escena están cerrados por una línea roja gruesa y nuestra propuesta es que, si enrollamos la parte noreste para pegarla a la noroeste, los personajes están formando un semicírculo alrededor del trono en el cual está incluido el espectador - marcado por una $\mathrm{X}$-, por lo cual hemos elaborado el esquema que se muestra en la figura 8 (ver figura 8).

El segundo gran grupo lo forman siete personajes ubicados en una plataforma alta sobre la cual se encuentra un trono (ver figura 9); tres figuras están sentadas sobre dicho trono - FH 1/18, 19 y $20-$ y no están interactuando entre sí. Asimismo, FH 1/17, sentado al pie del trono, levanta la cabeza hacia FH 1/18 como escuchándola, mientras el último personaje - FH l/2lestá de pie y de perfil, pero no parece interactuar con los demás.

Vemos que $\mathrm{FH} \mathrm{l} / 19$, sentado con las piernas cruzadas, de frente y ligeramente inclinado hacia su derecha, ocupa un volumen más amplio que sus acompañantes y está rodeado también de más espacio vacío. Su cráneo rasurado y alargado según la tradición maya lo hace

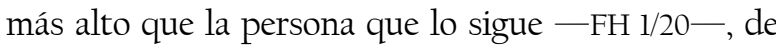
manera que se muestra así una sutil jerarquía en el trono mismo. Viste una falda blanca y un huipil hecho 
de gasa transparente, con diseños de rombos negros en la parte inferior, símbolos geométricos blancos en la parte superior y un borde de color verde. Está "enmarcado" por dos cartuchos sin glifos. Por otro lado, el elemento triangular que se encuentra detrás es la "lengua" de un mascarón pintado en la parte superior y que traspasa los límites impuestos por la línea roja. En un artículo anterior (Pincemin, 2008: 68), hemos mostrado las diferentes interpretaciones dibujadas de dicho mascarón y es interesante notar que la copia de Villagra no muestra este elemento, mientras que la de Tejeda sí, pero se para en la línea roja. Por lo que hemos podido observar, el único personaje humano que tiene elementos que traspasan los planos es Yajaw Chaan Muwan II, el gobernante. Por todas estas razones identificamos a FH 1/19 como tal. Los dos personajes que lo rodean son más bajos y FH 1/18 todavía más que FH 1/20: la primera figura está sentada en loto, con una mano bajo el mentón y la otra posada sobre el trono en una graciosa pose. Su pelo, de color rojo, está anudado en una cola de caballo sobre la parte superior del cráneo, lo que resalta también su perfil. Viste un huipil transparente de color verde con diseños geométricos que asemejan máscaras del dios Tláloc. Parece estar hablando con FH 1/17. FH 1/20 está sentada de perfil y viste un huipil amarillo con escote en los hombros, cubierto por otro huipil de gasa transparente con diseños en rojo. Su estatura es ligeramente más baja que la del gobernante. En la estela 2 y en el cuarto 2 se representan dos mujeres, una la madre y la otra la esposa de Yajaw Chaan Muwan; suponemos que los dos personajes que acabamos de describir son aquéllas. FH 1/18 sería la esposa por su cercanía al heredero y porque su actitud más dinámica y su pose hacen que parezca más joven que la otra — según nuestro criterio occidental, claro está-.

Queda, para terminar esta escena y este grupo, el personaje de pie que se encuentra al lado del trono y cerca de un gran bulto que contiene granos de cacao. Viste una falda blanca y un huipil de gasa transparente con motivos geométricos en blanco, uno de los cuales, la "estrella espinosa", se sigue utilizando en los textiles de Venustiano Carranza en Chiapas. Es un hombre con el torso desnudo pero que, al igual que el gobernante y su familia, porta este huipil especial. Dadas las dificultades para hilar el hilo de algodón tan delgado y tejerlo de manera tan abierta, nos parece que este tipo de atuendo estaba reservado a las personas más importantes (Pincemin, 2002). Por otro lado, su cabeza está prácticamente a la misma altura que la de la esposa. Estamos entonces frente a un personaje muy importante en la corte de Yajaw Chaan Muwan II, pero del cual no sabemos nada — quizás un pariente muy cercano que fungiría como "primer ministro"-.

\section{Conclusiones}

El trabajo de examinar elementos de cada escena de los murales como parte de las unidades semióticas nos permite adentrarnos en la lógica interna de las imágenes y nos enseña a verlas cada vez mejor, a dudar de nuestra visión, a cuestionar lo que creíamos saber y a aumentar nuestra admiración hacia la cultura que creó estas obras.

Para el análisis semiótico hemos utilizado elementos como la proxémica — sobre todo, menor o mayor espacio alrededor de uno- y oposiciones como alto/ bajo, masculino/femenino, adulto/joven, a las cuales hemos agregado la existencia o no de cláusula glífica y las diferencias entre ellas - con o sin marco- para proponer un primer acercamiento a la comprensión del poder entre los mayas de Bonampak a partir de sus propias imágenes, lo que nos permite distinguir, por ejemplo, las sutiles jerarquías de la corte transmitidas por el pincel de un pintor anónimo bajo la coordinación del maestro de Bonampak retratado en el cuarto 3 (Pincemin, 1994: 133). Para un mayor entendimiento todavía, nos faltaría aquí, entre otros elementos, el uso del color y su simbolismo, las descripciones precisas de cada uno de los personajes y la visión de conjunto, pero, como lo decíamos al inicio, esto es solamente un ejemplo del estudio que estamos aplicando a la totalidad de los murales.

\section{Notas}

${ }^{1}$ Por razones de edición, en este artículo usaremos dibujos en blanco negro, y no en color, aunque somos 
conscientes de la importancia de este último en el estudio. Por otra parte, y por razones de derecho de autor, los dibujos presentados son nuestras calcas hechas en 1988 y revisadas en los últimos años.

${ }^{2}$ Parte de la kinésica (lenguaje corporal) que se refiere a las distancias entre personas.

\section{Referencias bilbiográficas}

Adams, Richard E.W. y Robert C. Aldrich (1978), "A Reevaluation of the Bonampak Murals: A Preliminary Statement on the Paintings and Texts", en Merle Greene Robertson (ed), Third Palenque Round Table, 1978, Austin: University of Texas Press, t. 2, pp. 45-59.

Anawalt, Patricia R. (1981), Indian Clothing Before Cortes: Mesoamerican Costumes from the Codices, Norman: University of Oklahoma Press.

Anawalt, Patricia R. (1996), "Atuendos del México antiguo", en Arqueología Mexicana, vol. III, núm. 17, México: Raíces, pp. 6-16.

Arellano, Alfonso (1998), "Bonampak. Cédulas", en L. Staines (coord.), La pintura mural prehispánica. II. Area maya. Bonampak, México: Instituto de Investigaciones Estéticas-UNAM, t. I, pp. 1-53.

Bargalló Isabel, Montserrat Bargalló (2011), "Iconografía y contexto: el caso de Mesoamérica”, en M. del C. Valverde y V. Solanilla (coords.), Las imágenes precolombinas: reflejo de saberes, México: UNAM, pp. 565-597.

Benveniste, Emile (1977), Problemas de lingüística general, México: Siglo XXI.

Biró, Péter (2005), "Sak Tz'i' in the Classic Period Hieroglyphic Inscriptions", en Mesoweb Publications. 〈www.mesoweb.com/articles/biro/SakTzi.pdf〉 [10 de mayo de 2013].

Brozzoli, Mario E. y Maureen Sánchez (2003), "La iconología en la arqueología: enfoque metodológico", en Ana Cecilia Arias Quirós et al. (coords.), II Congreso sobre Pueblos Indígenas. Del conocimiento ancestral al conocimiento actual: visión de lo indígena en el umbral del siglo XXI, Costa Rica:
Universidad de Costa Rica.

De la Fuente, Beatriz (1995), "La guerra en las pinturas de Bonampak: iregistro histórico o memoria mítica?", en A. Pascual Soto (ed.), Arte y violencia. Estudios de Arte y Estética, México: Instituto de Investigaciones Estéticas-UNAM, pp. 451-468,

De la Garza, Mercedes (1984), El universo sagrado de la serpiente entre los mayas, México: Instituto de Investigaciones Filológicas-Centro de Estudios Mayas-UNAM.

De la Garza, Mercedes (1985), Aves sagradas de los mayas, México: Instituto de Investigaciones FilológicasCentro de Estudios Mayas-UNAM.

Dondis, Donis A. (2003), La sintaxis de la imagen. Introducción al alfabeto visual, Barcelona: G. Gili.

Eco, Umberto (1986), La estructura ausente. Introducción a la semiótica, Barcelona: Lumen.

Eco, Umberto (1990), Semiótica y filosofía del lenguaje, Barcelona: Lumen.

Espinosa, Agustín et al. (1988), Bonampak, México: Citicorp-Citibank.

Francastel, Pierre (1988), La realidad figurativa. I El marco imaginario de la expresión figurativa, Barcelona: Paidos Estética.

González Ochoa, César (1986), Imagen y sentido. Elementos para una semiótica de los mensajes visuales, México: Instituto de Investigaciones Filológicas-UNAM.

Guiraud, Pierre (1986), La semiología, México: Siglo XXI.

Jackson, Margaret A. (2011), "El nexo entre la notación, las imágenes y el ritual en el arte moche del Perú", en M. del C. Valverde y V. Solanilla (coords.), Lasimágenes precolombinas: reflejo de saberes, México: UNAM, pp. 397-419.

Kubler, George (1969), Studies in Classic Maya Iconography, New Haven: Academy of Arts and Science.

Larín Lydia, Gisela Balassa (2001), Museo del Traje Mexicano. 1. El mundo prehispánico, México: Clío/Sears.

Leach, Edmund (1981), Cultura y comunicación. La lógica de la conexión de los símbolos, México: Siglo XXI.

Leroi-Gourhan, André (1965), Le geste et la parole. La mémoire et les rythmes, París: Sciences Daujourd'hui/ Albin Michel.

Le Fort, Genevieve (2002), "El traje real entre los Mayas 
de la época clásica (250-900 d. C.)", en Actas de las IIas Jornadas Internacionales sobre Textiles Precolombinos, Barcelona: Solanilla Demestre, pp. 27-41.

Lombardo de Ruíz, Sonia (1998), "Tradición e innovación en el estilo de Bonampak”, en L. Staines (coord.), La pintura mural prehispánica. II. Área maya. Bonampak, México: Instituto de Investigaciones EstéticasUNAM, t. II, pp. 2l-48.

Lombardo de Ruíz, Sonia (1976), "Análisis formal de las pinturas de Bonampak", en Actas del XLI Congreso Internacional de Americanistas, México: Instituto Nacional de Antropología e Historia, pp. 365-379.

Magariños, Juan (2001), "Semiótica de las imágenes visuales 2. La recuperación de la memoria visual", en Archivo Virtual de Semiótica. 〈http://www.archivosemiotica.com.ar/imagenes.html> [10 de mayo de 2013].

Marty, Robert (2001), La sémiotique selon Robert Marty, 〈http://www.univ-perp.fr/see/rch/lts/marty/pregl. htm> [10 de mayo de 2013].

Mastache, Alba Guadalupe (1971), Técnicas prehispánicas del tejido, México: INAH.

Mathews, Peter (1980), "Notes on the Dynastic Sequence of Bonampak, Part l", en Third Palenque Round Table, 1978, Austin: University of Texas Press, t. 2, pp. 60-73.

Miller, Mary Ellen (1986), The Murals of Bonampak, Princeton: Princeton University Press.

Miller, Mary Ellen (1995a), "Maya Masterpiece Revealed at Bonampak", en National Geographic Magazine, vol. 187, núm. 2, pp. 50-69.

Miller, Mary Ellen (1995b) "Bonampak", en Arqueología Mexicana, vol. III, núm. 16, México: INAH, pp. 48-55.

Miller, Mary Ellen y Stephen D. Houston (1998), "Algunos comentarios sobre las inscripciones jeroglíficas en las pinturas de la Estructura 1 de Bonampak", en L. Staines (coord.), La pintura mural prehispánica. II. Área maya. Bonampak, México: Instituto de Investigaciones Estéticas-UNAM, t. II, pp. 245-254.

Panofsky, Erwin (1984), Estudios sobre iconología, México: Alianza Editorial.

Pérez Campa, Mario y Mauricio Rosas Kifuri (1987), “Dos nuevas piedras labradas de Bonampak", en Memorias del Primer Coloquio Internacional de Mayistas, México: Instituto de Investigaciones Filológicas-Centro de Estudios Mayas-UNAM, pp. 749-773.

Pérez Martínez, Herón (2011), Apuntes para el seminario Semiótica de la Cultura, Chiapas: Facultad de Ciencias Sociales-UNACH.

Pérez Martínez, Herón (2009), En pos del signo. Introducción a la semiótica, México: El Colegio de Michoacán.

Pincemin Deliberos, Sophia (1998), "Indumentaria ritual maya en el siglo VIII", en Memorias del Tercer Congreso Internacional de Mayistas, México: Instituto de Investigaciones Filológicas-Centro de Estudios Mayas-UNAM, pp. 382-387.

Pincemin Deliberos, Sophia (2002), "De textiles y estatus o a cada quien su vestido: Bonampak, 790 d.C.", en Memoria de la IV Mesa Redonda de Palenque, México: INAH/PARI.

Pincemin Deliberos, Sophia (2008), "Miradas diferentes o el arte de ver en los murales de Bonampak, Chiapas", en Alejandro Sheseña, Sophia Pincemin y Carlos Uriel del Carpio (coords.), Estudios del patrimonio cultural de Chiapas, Tuxtla Gutiérrez: UNICACH, pp. 57-84.

Pincemin Deliberos Sophia y Mauricio Rosas Kifuri (1994), "Algunos apuntes sobre la iconografía de Bonampak, Chiapas”, en Cuarto Foro de Arqueología de Chiapas, Tuxtla Gutiérrez: Instituto Chiapaneco de Cultura-Gobierno del Estado de Chiapas, pp. 131-143.

Pincemin Deliberos Sophia y Mauricio Rosas Kifuri (2005), "La batalla de Bonampak: nuevas interpretaciones, en Bolom, Revista del Centro de Investigaciones Frans Blom, núm. 2, pp. 7-23.

Prous, André (2002), "Stylistic Units in Prehistoric Art Research. Archeofacts or realities?", en Rupestre/web, 〈http://rupestreweb-tripod.com/prous.html > [10 de mayo de 2013].

Rosas Kifuri, Mauricio (1988), "Epigrafía e iconografía”, en Agustín Espinosa et al. (1988), Bonampak, México: Citicorp-Citibank, pp. 41-53.

Ruppert, Karl, J. Eric S. Thompson y Tatiana Proskouriakoff (1955), Bonampak, Chiapas, México, Washington: Carnegie Institution of Washington. 
Seler, Eduard (2002), Las imágenes de animales en los manuscritos mexicanos y mayas, México: Juan Pablos.

Staines Cicero, Leticia (coord.) (1998), La pintura mural prehispánica en México II. Área maya, 2 vols. México: Universidad Nacional Autónoma de México-Instituto de Investigaciones Estéticas.

Tovalín Ahumada, Alejandro (2013), La organización social de Bonampak a través del patrón de asentamiento (tesis inédita de maestría en historia), UNACHUNICACH, Tuxtla Gutiérrez.
Valverde Valdés, María del Carmen (2004), Balam. El jaguar a través de los tiempos y los espacios del universo maya, México: UNAM-Instituto de Investigaciones Filológicas-Centro de Estudios Mayas.

Valverde Valdés, María del Carmen y Victoria Solanilla Demestre (coords.) (2011), Lasimágenesprecolombinas. Reflejo desaberes, México: Centro de Estudios Mayas-IIF-UNAM.

Yale Peabody Museum of Natural History (s.f.), "The Maya Murals of Bonampak: Windows on an Ancient Culture". 〈http://peabody.yale.edu/exhibits/mayamurals-bonampak> [10 de mayo de 2013]. 


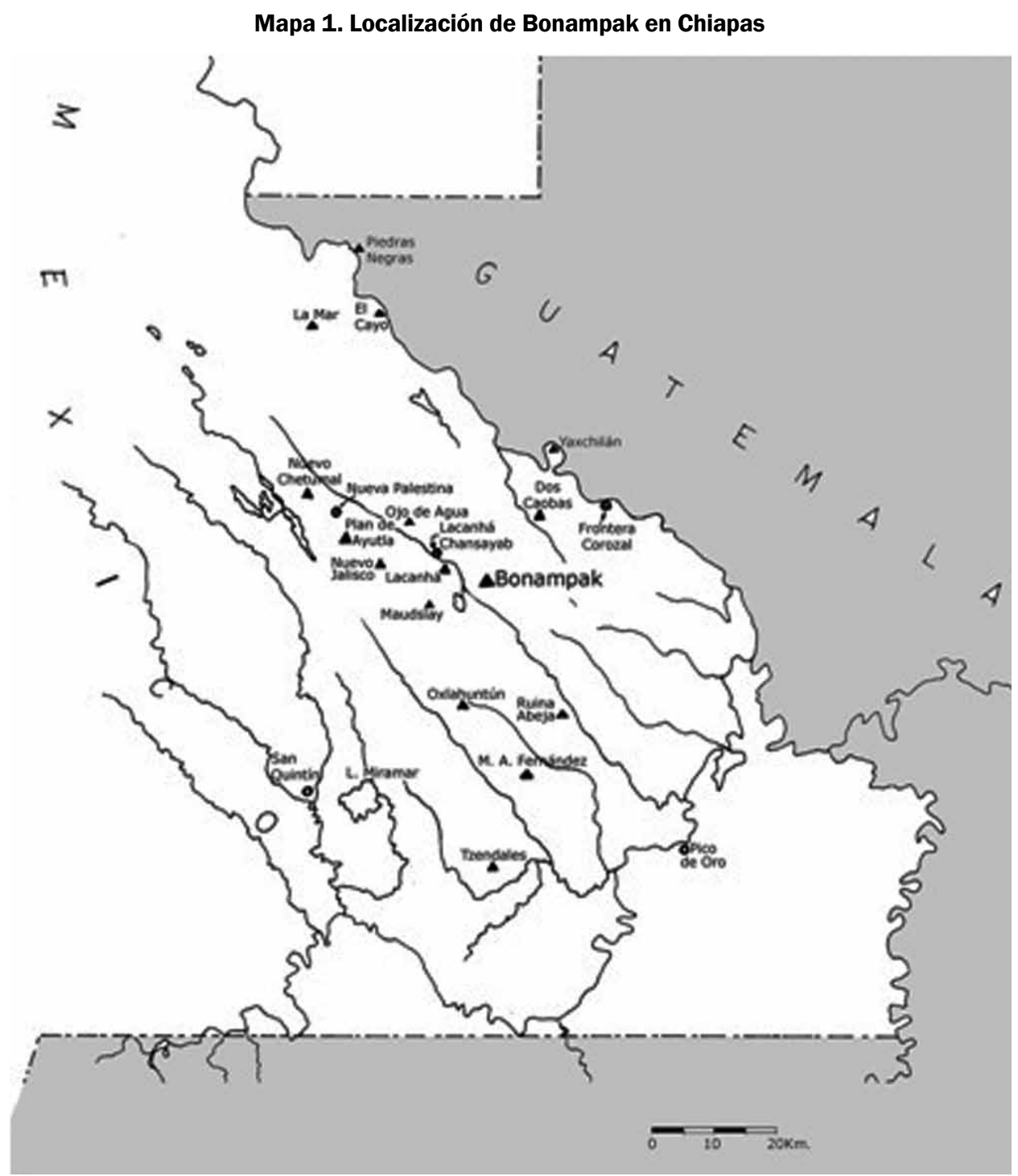

Fuente: Tovalín (2013, fig. 4.1). 
Mapa 2. Plaza central de Bonampak

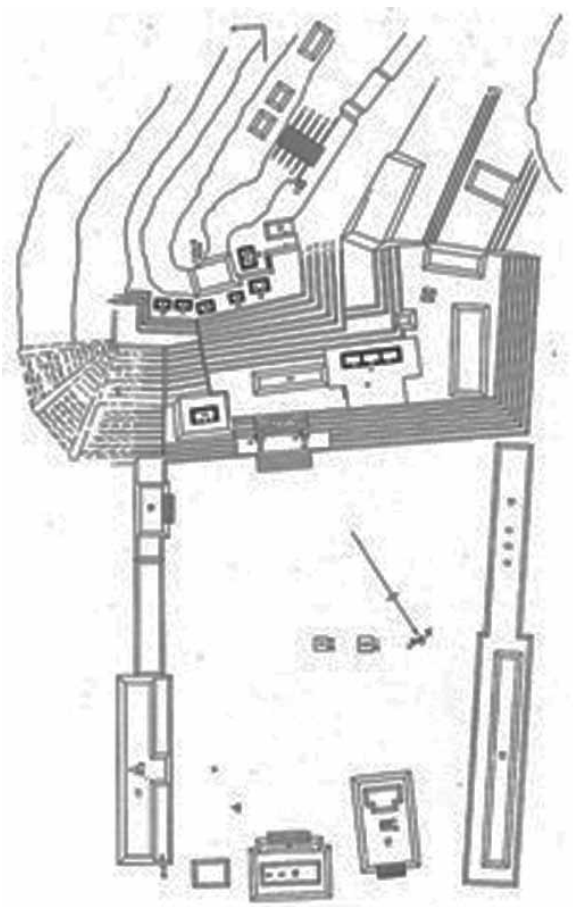

La estructura a la izquierda es el Edificio de las Pinturas o Estructura 1. Fuente: Ruppert, Thompson y Proskouriakoff (1955).

Figura 1. Croquis de la fachada de la Estructura 1, Bonampak

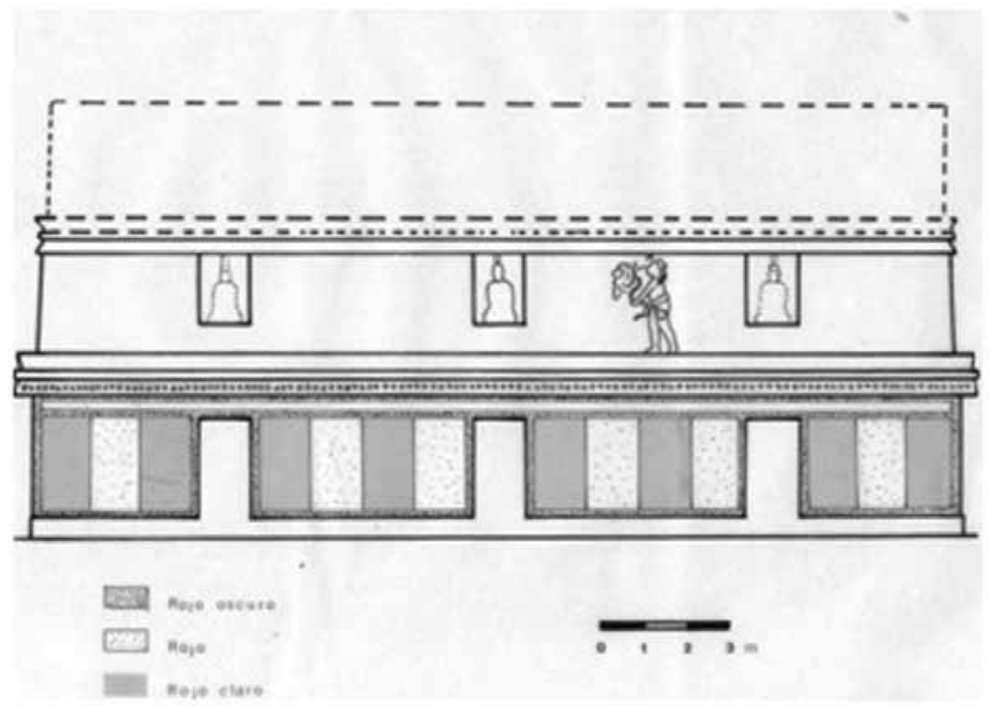

Fuente: Sophia Pincemin. 
Figura 2. Cuarto 1, escena 1: los cuatro niveles
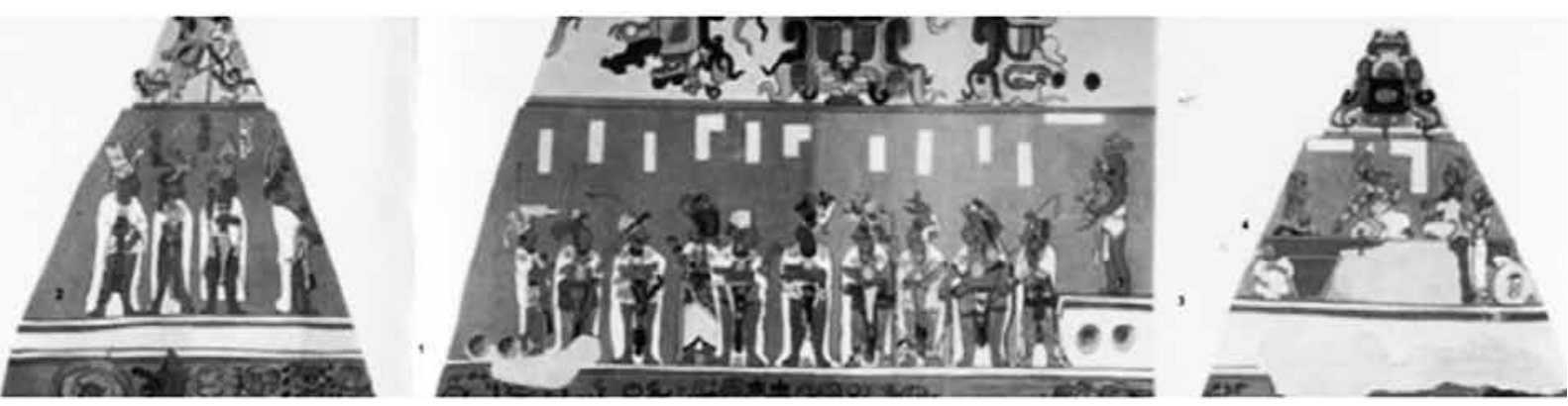

Fuente: A. Tejeda. 2: muro este; 1: muro sur; 3: plataforma del trono; 4: trono.

Figura 3. Cuarto 1, escena 1: repartición de los personajes en cuatro niveles

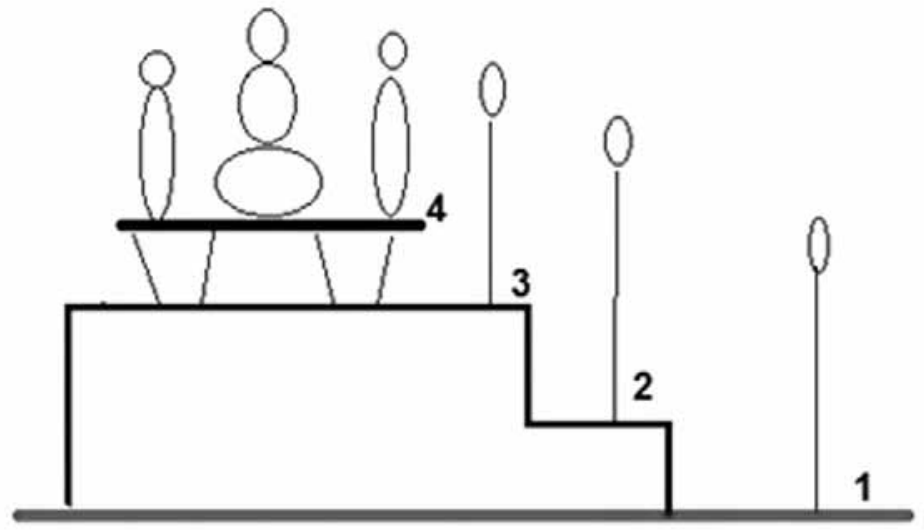

Fuente: Sophia Pincemin. 
Figura 4. FH 1/1 a 1/ 4, cuarto 1, Bonampak

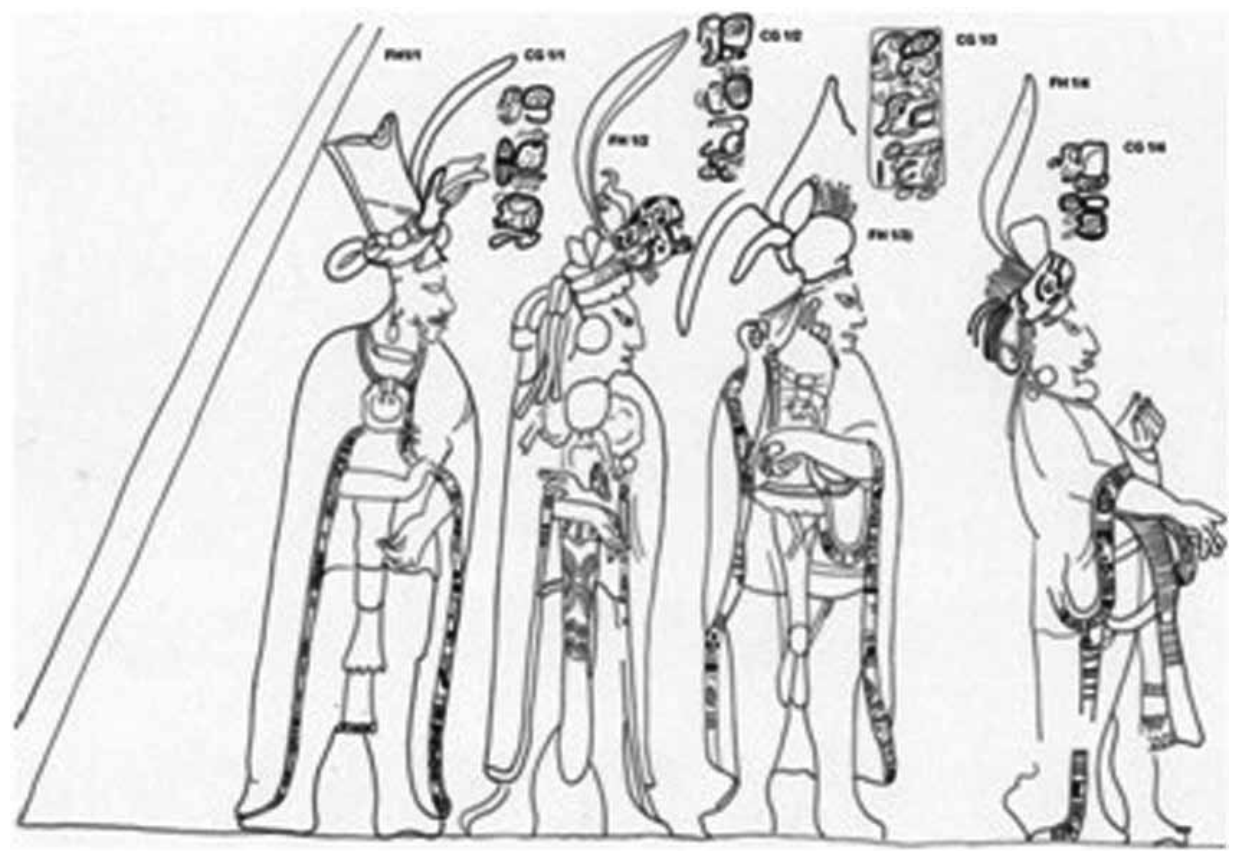

Fuente: Sophia Pincemin.

Figura 5. FH 1/5 a 1/8, cuarto 1, Bonampak

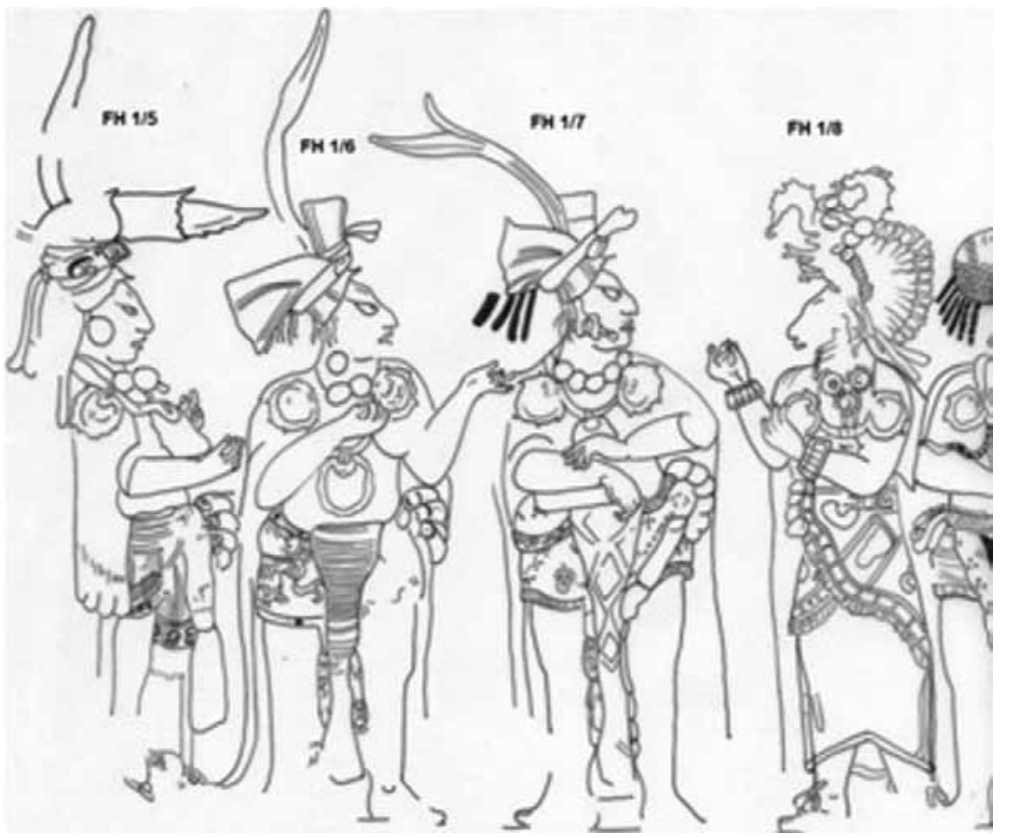

Fuente: Sophia Pincemin. 
Figura 6. FH 1/9 a FH 1/14, cuarto 1, Bonampak

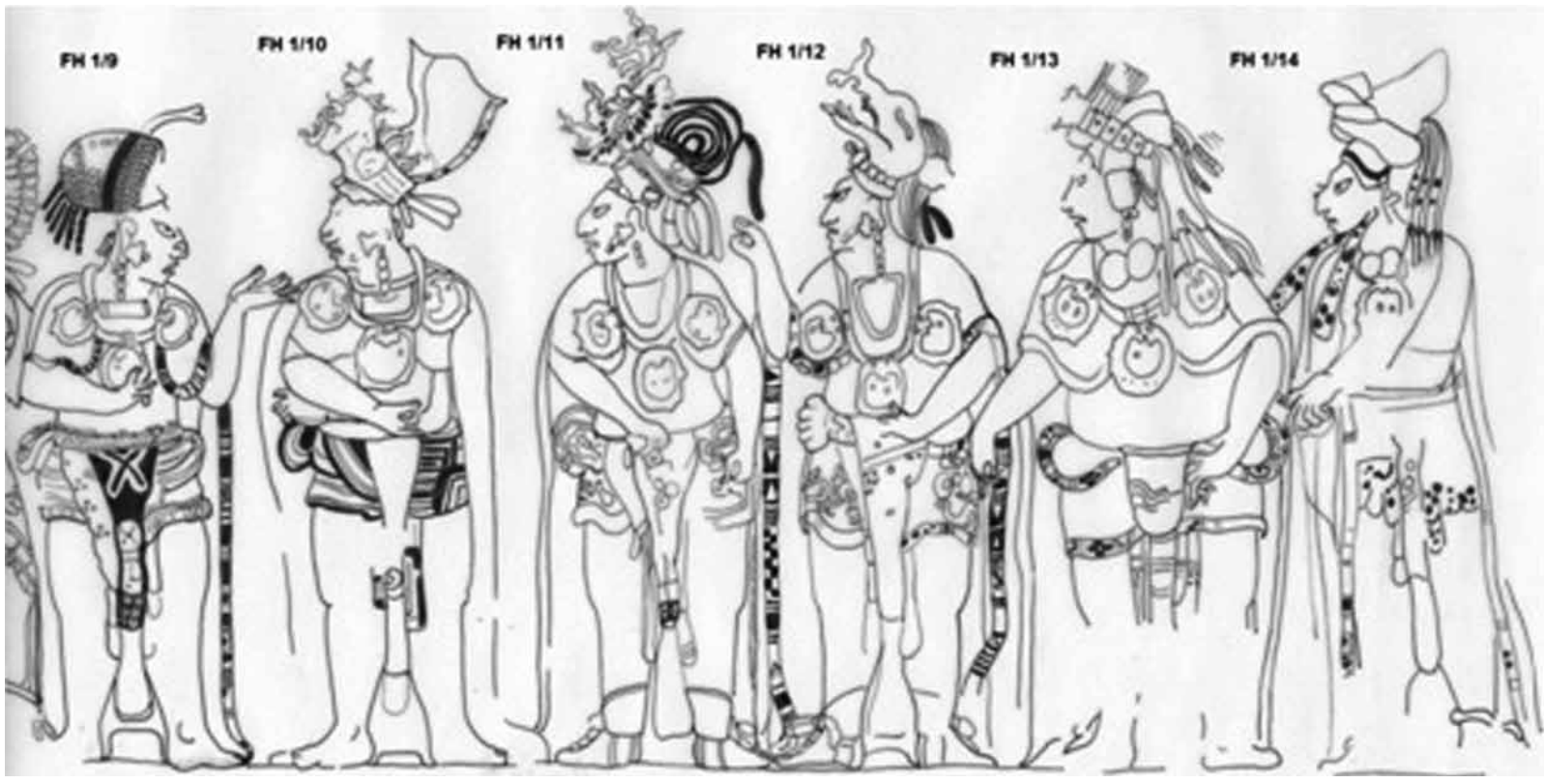

Fuente: Sophia Pincemin.

Figura 7. Cuarto 1, escena 1: FH 1/15 y 1/16

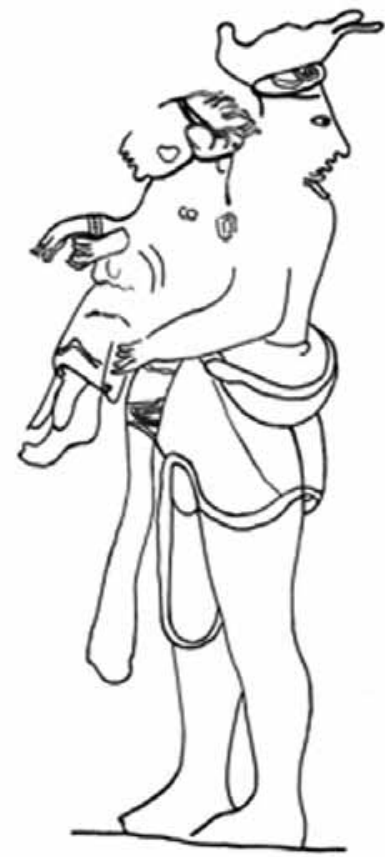

Fuente: Sophia Pincemin. 
Figura 8. Croquis de posición de los personajes de la escena 1, cuarto 1

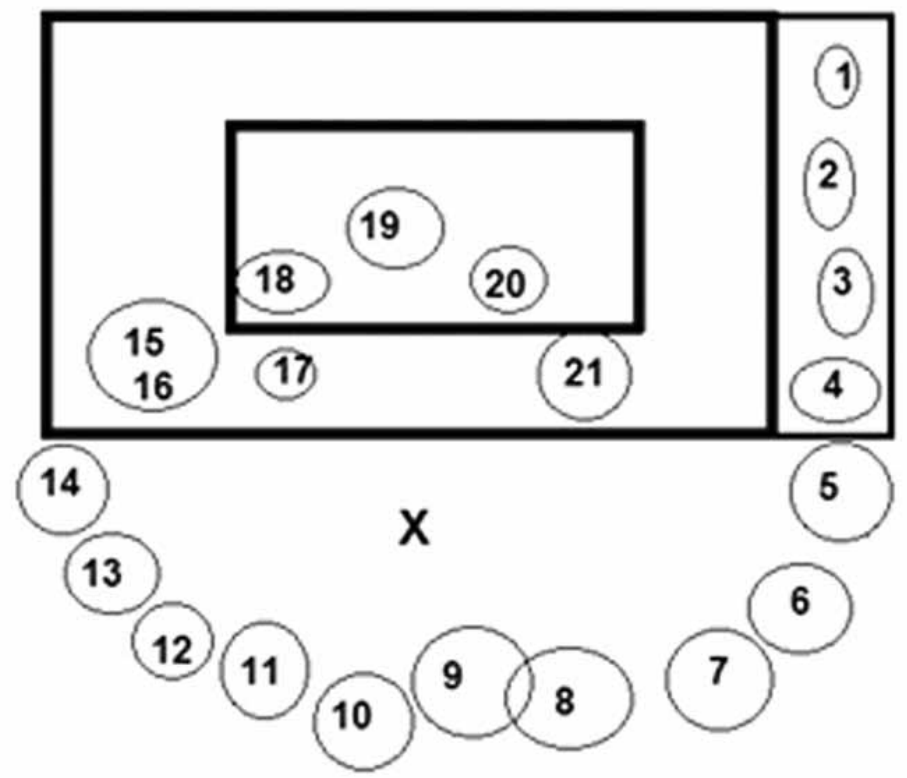

Fuente: Sophia Pincemin.

Figura 9. FH 1/17 a 1/21, cuarto 1, Bonampak

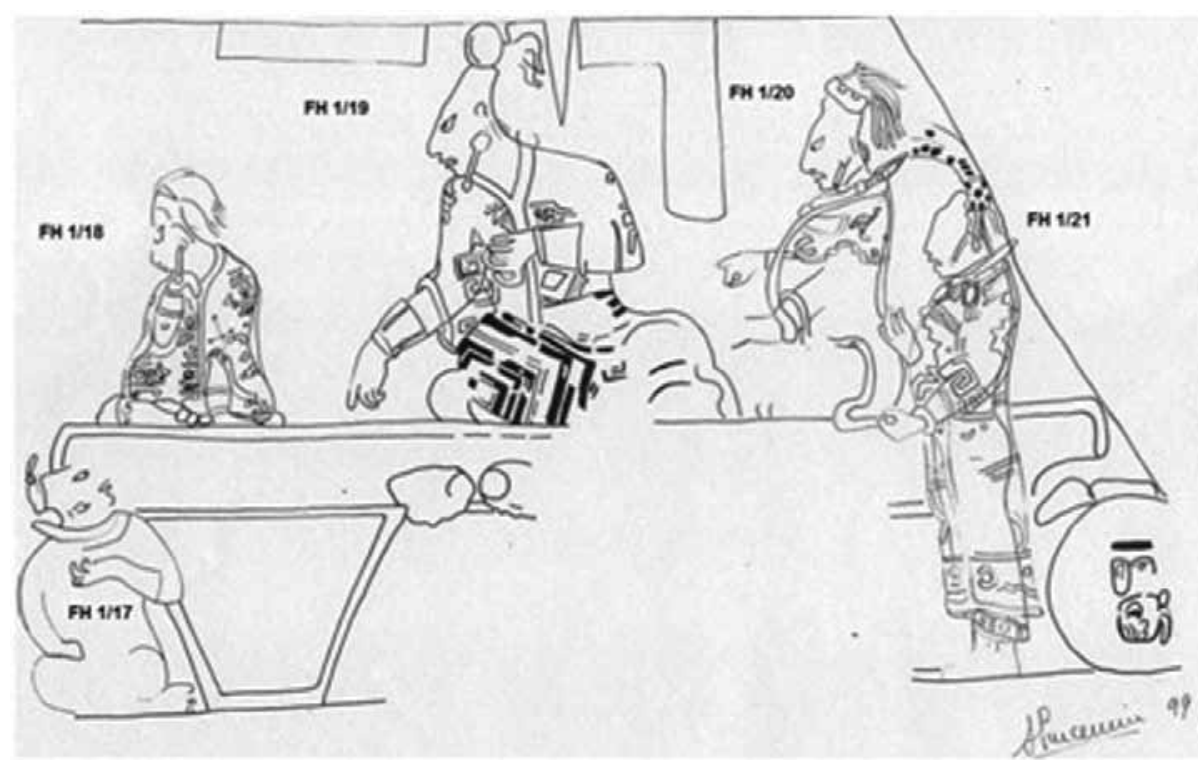

Fuente: Sophia Pincemin. 